\title{
Cognitive deficits in the Steele-Richardson-Olszewski syndrome (progressive supranuclear palsy)
}

\author{
ER MAHER, EILEEN M SMITH, AJ LEES \\ From the National Hospitals for Nervous Diseases, Queen Square and Maida Vale, London, and University \\ College Hospital, London, UK.
}

SUMmaRy Clinical examination of 33 consecutive newly diagnosed cases of Steele-RichardsonOlszewski syndrome revealed evidence of cognitive impairment in 20. Eighteen of the 27 right handed patients who underwent neuropsychological assessment had intellectual impairment (mild in nine and marked in nine patients). The pattern of abnormalities was similar to but more severe than those previously reported in Parkinson's disease, with particular difficulties in carrying out tests which are believed to be sensitive to frontal lobe dysfunction.

In 1964, Steele, Richardson and Olszewski ${ }^{1}$ reported the neuropathological and clinical features of a previously unrecognised syndrome which they called Progressive Supranuclear Palsy. Dementia, usually mild, was present in seven of the original nine patients and the presence of cognitive deficits and personality change have subsequently been confirmed. ${ }^{2-7}$ However, the exact frequency, severity and type of neuropsychological impairment is still controversial. Most studies have relied on clinical examination or impression to diagnose dementia and a large series of consecutive patients has never been studied. In studies in which neuropsychological testing has been carried out it has been claimed that the performance of patients with the SteeleRichardson-Olszewski (SRO) syndrome was only impaired on tests requiring visual scanning ability and that otherwise there was no evidence of intellectual or memory impairment. ${ }^{89}$ We therefore reviewed the neuropsychological reports in a group of newly diagnosed cases of SRO syndrome seen at the National Hospitals for Nervous Diseases between 1975 and 1984 to determine the incidence and extent of intellectual impairment.

\section{Methods}

The clinical records of 33 consecutive admissions to the National Hospitals for Nervous Diseases with a new diag-

Address for reprint requests: Dr AJ Lees, the National Hospitals for Nervous Diseases, Queen Square, London WC1N 3BG, UK.

Received 16 November 1984 and in revised form 1 March 1985. Accepted 8 March 1985 nosis of SRO syndrome were reviewed retrospectively. All patients had unequivocal evidence of the syndrome, with supranuclear palsy affecting at least downgaze and some or all of the following features: pseudobulbar palsy, axial and/or limb rigidity, bradykinesia, dementia, pyramidal signs and gait disorder. Neuropsychological assessment was performed on 29 patients, of whom 27 were known to be right-handed and these were selected for further examination. These 27 dextral patients had been studied in the Department of Psychology at the time of diagnosis. All patients were assessed on four verbal subtests (vocabulary, digit span, arithmetic and similarities) of the Wechler Adult Intelligence Scale (WAIS), 20 were assessed on three performance subtests (picture completion, block design and picture arrangement) of the WAIS ${ }^{10}$ and an estimate of premorbid IQ was obtained in 19 patients from the National Adult Reading Test (NART)." Seven patients did not complete the three WAIS performance subtests because of visual difficulties (oculomotor abnormalities in four patients, blepharospasm in two patients and one patient did not have her spectacles). The WAIS IQ and subtest scores given are age-corrected.

Verbal and visual memory was examined using a Recognition Memory Test. ${ }^{12}$ Twelve patients completed both sections of this test and seven completed the verbal section only because of visual impairment.

Supplementary tests performed by some patients included the Graded Difficulty Naming Test $^{13}$ (nine patients), the Unusual Views test ${ }^{14}$ (14 patients) and the Fragmented Letters test ${ }^{\prime s}$ (11 patients), for perceptual deficits, and two tests of reputed frontal lobe function: verbal fluency (number of words beginning with " $s$ " in 90 seconds) (10 patients) and the Weigl test ${ }^{16}$ (11 patients). The number and type of supplementary tests administered to a subject was generally determined by the current neuropsychological testing protocol and not by specific clinical indications.

The clinical and neuropsychological findings in two 
patients under the care of one of us (AJL) are reported in detail to illustrate some of the commoner features.

CT scans were performed and reported on in the Department of Neuroradiology. EEGs were recorded in the Department of Neurophysiology and were independently reviewed by Dr CJ Fowler and Dr MJG Harrison.

Statistical analyses comprised two-tailed $t$ testing for paired data.

\section{Patient details}

The 27 patients ( 11 males and 16 females) were aged from 55 to 78 (median 65 , mean 64.4) years of age and the median duration of symptoms before diagnosis was 3 years (range 1 to 9 years). Twenty-one patients had complained of mental symptoms: memory impairment (13 patients), emotional lability (7), depression (6) and slower mentation (4). Personality changes were reported by the relatives of four patients (apathetic or withdrawn: four patients, irritability in one patient).

Evidence of intellectual impairment and memory disturbance was considered to be present on clinical examination in 17 of the 27 patients. Clinical examination of the four patients who were not neuropsychologically assessed showed evidence of intellectual impairment in three (marked in two, mild in one patient).

Eight of the 27 patients were receiving neurotropic medication at the time of neuropsychological assessment (levodopa and decarboxylase inhibitor preparation six patients, benzhexol three patients and amantadine one patient).

CT scans were performed on all patients and showed evidence of cerebral atrophy and ventricular dilatation in 23 of the 27 patients (mild in 15 patients, moderate in seven patients and marked in one patient).

Seventeen patients had had an EEG recorded. None of the records were markedly abnormal. Eight records were normal, six were mildly abnormal (slight slowing or low amplitude alpha rhythm, minor scattered theta activity) and three were more notably abnormal (two showed asymmetrical excess theta activity and one showed nonspecific frontal theta activity on hyperventilation.

\section{Results}

\section{WAIS testing}

The mean reading, verbal, performance and fullscale IQ scores are given in table 1 . For the patients who completed both tests, there was a significant difference between the NART and verbal IQ scores $(n=19 t=4.46 p<0.001)$, the NART and Performance IQ scores $(n=16 t=6.76 p<0.001)$, the NART and full scale IQ scores $(n=17 t=6.68 \mathrm{p}<$ 0.001 ) and the verbal and performance IQ scores ( $n$ $=20 \mathrm{t}=3.74 \mathrm{p}<0.001)$.

The discrepancy between the NART and the Full-scale IQ (calculated from the verbal IQ for the three patients who had not attempted the performance scale) score was recorded as an index of deterioration in 19 patients. The mean (+SD) discrepancy was $13 \cdot 3(+10 \cdot 1)$, six patients were consi-
Table 1 Mean NART and WAIS scores

\begin{tabular}{|c|c|c|c|}
\hline Test & $\begin{array}{l}\text { No } \\
\text { patients }\end{array}$ & $\begin{array}{l}\text { Score } \\
\text { mean }\end{array}$ & $+S D$ \\
\hline $\begin{array}{l}\text { NART Score: } \\
\text { (IO equivalent) }\end{array}$ & 19 & 113 & +9.33 \\
\hline $\begin{array}{l}\text { Verbal IQ } \\
\text { Performance IQ } \\
\text { Full scale IQ } \\
\text { WAIS Subtest Score: }\end{array}$ & $\begin{array}{l}27 \\
20 \\
20\end{array}$ & $\begin{array}{r}100 \cdot 5 \\
90 \cdot 3 \\
94 \cdot 3\end{array}$ & $\begin{array}{l}+15.6 \\
+13.8 \\
+13.1\end{array}$ \\
\hline $\begin{array}{l}\text { Vocabulary } \\
\text { Digit Span } \\
\text { Arithmetic } \\
\text { Similarities } \\
\text { Picture Completion } \\
\text { Block Design } \\
\text { Picture Arrangement }\end{array}$ & $\begin{array}{l}27 \\
27 \\
27 \\
27 \\
21 \\
22 \\
20\end{array}$ & $\begin{array}{r}10 \cdot 33 \\
9 \cdot 19 \\
8 \cdot 26 \\
8 \cdot 26 \\
6 \cdot 76 \\
5 \cdot 91 \\
4 \cdot 21\end{array}$ & $\begin{array}{l}+2.79 \\
+2.76 \\
+3.28 \\
+3.27 \\
+2.10 \\
+2.52 \\
+3.31\end{array}$ \\
\hline
\end{tabular}

dered to have a mild degree of intellectual deterioration (index of deterioration between 10 and 20) and six patients were considered to have marked index of deterioration (over 20). In the remaining eight patients comparison of the current WAIS scores with the estimated premorbid level of function (as assessed from the educational and occupational history), was considered to show evidence of intellectual deterioration in six patients (mild in three and marked in three patients).

In two patients the verbal and performance IQ scores were both in the defective range (less than 70).

Analysis of the WAIS subtest scores (table 1) showed that the highest mean score was obtained on vocabulary and the lowest on picture arrangement. Multiple paired $t$ tests were applied to determine if the differences between the mean subtest scores were statistically significant: the differences between the scores for the digit span, arithmetic and similarities subtests were not significant $(p>0 \cdot 1)$, but the mean scores for all three subtests were significantly lower than that for the vocabulary subtest $(t=2.1 \mathrm{p}<0.05, t=3.4 \mathrm{p}<0.01$ and $t=4.98$ $\mathrm{p}<0.001$ respectively). Because of visual difficulties not all subjects completed the performance subtests.

Those that completed the Block Design or Picture Arrangement subtests scored significantly lower on these tests than they did for each of the verbal subtests $(p<0.001)$. Those that attempted the Picture Completion subtest scored significantly lower on this test than they did on the vocabulary $(t=7.61 \mathrm{p}<$ $0.001)$, digit $\operatorname{span}(t=4.98 \mathrm{p}<0.001)$ and arithmetic $(t=2.23 \mathrm{p}<0.05)$ subtests, and significantly higher on this test than on the Block Design $(t=$ $2.74 \mathrm{p}<0.02)$ and Picture Arrangement $(t=4.9 \mathrm{p}$ $<0.001)$ subtests.

Comparison of the results of neuropsychological testing with the CT scan appearances failed to reveal any correlation between the severity of intellectual impairment and the degree of cerebral atrophy. 


\section{Memory}

The verbal version of the Recognition Memory Test $^{12}$ was administered to 19 patients and the visual version to 12 patients. On the verbal test the mean score $(+S D)$ was $39( \pm 7 \cdot 4), 12$ patients scored at an average level or above, three were weak and four scored at a chance level indicating severe memory impairment. The mean score $(+S D)$ on the visual test was $34.4( \pm 7 \cdot 6)$. In only three patients was there a significant selective memory deficit on the visual version of the test and there were no instances of a selective verbal deficit. ${ }^{12}$

\section{Language functions}

Mild word-finding difficulties were found in seven of the 25 patients, but there was no evidence of more severe dysphasia or comprehension difficulties. The Graded Difficulty Naming Test ${ }^{13}$ was given to nine patients. Two patients scored in the superior range, six in the average range and one in the dull-normal range.

\section{Mental speed}

In three patients marked slowness of thought out of proportion to intellectual impairment was noted. One patient was noted to have an involuntary tendency to speed up, often when speaking, but particularly when using her hands.

\section{Perception}

Visual Perceptual decoding processes were examined using the Unusual Views test ${ }^{14}(n=14)$ and/or the Fragmented Letters test ${ }^{15}(n=11)$. Nine of the 14 patients scored within normal limits on the Unusual Views test (mean 15.8/20) and nine of 11 patients scored within normal limits on the Fragmented Letters test (mean 17.8/20). The mean (+SD) Performance IQ and Picture Arrangement subtest scores for the 10 patients who scored within normal limits on the Unusual Views and/or Fragmented Letters was $92.7(+11.9)$ and $3.9(+3.48)$ respectively.

\section{Frontal lobe test}

The test of verbal fluency was administered to 10 patients and was failed by seven (all named 14 or less words beginning with " $\mathrm{s}$ " in 90 seconds). The Weigl test ${ }^{16}$ was administered to 11 patients and was failed by seven, one of whom also displayed reflex grasping. Reflex grasping was found in a further five patients, one of whom also exhibited utilisation behaviour. ${ }^{17}$

\section{Case reports}

Case 1 A 59-year-old man presented with a 3 year his- tory of progressive unsteadiness of gait with a tendency to fall backwards, dysarthria and dysphagia. For 6 months he had noticed diplopia in the vertical plane. His wife complained that there had been a gradual onset of mental slowing, emotional lability and inappropriate behaviour. On examination, he was noted to have a staring vacant expression and to hold his head rigid. He walked with a stiff upright gait and tended to lean backwards. Examination of higher mental function showed no definite abnormality although mentation was slow. There was no dysphagia. Ocular movements to command in the vertical plane were absent and following movements were limited to $10^{\circ}$ upgaze and $5^{\circ}$ downgaze. Horizontal eye movements were full but slow. Convergence was absent, but oculocephalic responses were full. A slurring dysarthria with limited palatal and spastic tongue movements, and an exaggerated gag reflex were present. The marked axial rigidity contrasted with the mild limb rigidity. Power and coordination were normal, but all tendon reflexes were pathologically increased with bilateral extensor plantar responses and marked pout and facial reflexes also present. A CT scan showed mild generalised cerebral atrophy and an EEG was within normal limits.

Neuropsychology: NART $=101$, verbal $I Q=80$, performance $\mathrm{IQ}=72$, index of deterioration $=25$. Analysis of subset scores showed that the highest scores were 8 for arithmetic and 7 for vocabulary. The lowest score was 0 for Picture Arrangement. He scored at chance level on both the verbal and visual versions of the Recognition Memory test (29/50 and 29/50), but scored within normal limits on the Fragmented Letters test for perceptual deficits. He was unable to sort Weigl shapes and perseverated on his first sorting.

Comment: Clinically this patient's neurobehavioural changes were consistent with a "subcortical" pattern of dementia. Neuropsychological testing showed evidence of marked intellectual impairment, affecting non-verbal skills more than verbal skills, and of memory impairment. There was no evidence of dysphasia or perceptual deficits, but frontal lobe function was impaired.

Case 2 This 64-year-old man gave a 4 year history of progressive slowing and unsteadiness of gait. Three years before admission a diagnosis of Parkinson's disease had been made and he had been started on Sinemet with little response. His speech became slurred, and he had noticed difficulty in looking down for six months. Examination revealed facial immobility and extreme neck rigidity. His gait was slow and shuffling with a tendency to fall backwards. Testing of higher mental function showed that he was fully orientated, but was slow and inaccurate on mental arithmetic and proverb interpretation was concrete. Eye movements to command and pursuit were restricted to $5^{\circ}$ upwards and downwards but lateral movements were full. Convergence was absent. Oculocephalic responses were full. He was dysarthric and tongue movements were slow and spastic. In the limbs there was mild rigidity, hyperreflexia and flexor plantar responses. CT scan showed moderate generalised cerebral atrophy. Test results were: NART $=104$, verbal $I Q=102$, performance $\mathrm{IQ}=84$, index of deterioration $=11$. Verbal subtest scores ranged from 12 for vocabulary to 5 for similarities. Performance subtest scores ranged from 6 for Picture 
completion to 0 for Picture arrangement. It was noted that in the latter test he "rationalised" his incorrect responses suggesting that his poor scores on non-verbal tests were not due to visual difficulties. On the verbal version of the Recognition Memory Test he scored at chance level (29/ 50), and although he could not concentrate long enough to complete the visual part of the test, this also seemed to be impaired. There was no evidence of nominal dysphasia (Graded Difficulty Naming test score was average) and he performed satisfactorily on the unusual views and Fragmented Letters test for perceptual deficits. However, he was completely unable to sort Weigl shapes.

Comment: neuropsychological testing suggested mild intellectual impairment with particular involvement of non-verbal skills. Memory was weak and there was evidence of frontal lobe dysfunction, but dysphasia or impairment of perceptual skills were not detected.

\section{Discussion}

In this study we have demonstrated that intellectual impairment can be detected by neuropsychological testing in most patients with SRO syndrome at the time of diagnosis. This conclusion is in agreement with the clinical observations of Steele et $a^{1}$ in their seminal paper. There are only a few reports of neuropsychological assessment in patients with the SRO syndrome, but most of these have shown evidence of some intellectual impairment (table 2). Impaired performance on neuropsychological tests might however conceivably result from severe dysarthria or visual difficulties. ${ }^{21}$

Oculomotor abnormalities might lead to difficulties on the WAIS performance but not verbal subtests. Fisk et $\mathrm{al}^{9}$ found no significant difference between the mean verbal IQ of normal controls and patients with SRO syndrome, and Kimura et al reported that intellectual impairment was unequivocal only on performance subtests which required visual scanning ability. In the present study both verbal and performance IQ scores were impaired when compared to the premorbid IQ. The impairment of verbal IQ cannot be explained by visual difficulties and none of the patients was markedly dysarthric. Furthermore, performance IQ was impaired in patients with normal perceptual decoding abilities suggesting that oculomotor abnormalities were unlikely to be predominantly responsible for the impaired performance on the Picture Arrangement, block design and picture completion subtests. The failure of Fisk $e^{a l^{9}}$ to find a significant difference between the SRO syndrome patients and controls was probably due to the small numbers studied (four in each group), as the mean verbal IQ for the SRO syndrome patients was 90.8 and 106 for the normal controls in their sample.

The main neuropathological feature of the SRO syndrome is the presence of neurofibrillary tangles and neuronal loss with gliosis in the basal ganglia, brain stem and cerebellar nuclei $(1,6)$. The neurofibrillary tangles are often morphologically different from those in Alzheimer's disease and are not usually accompanied by senile plaques. ${ }^{22}$ Both diseases have, however, neuronal loss in the nucleus basalis of Meynert. ${ }^{23}$ Although neurofibrillary tangles have been found in the temporal and frontal cortex of patients with the SRO syndrome, ${ }^{6}$ cortical changes are infrequent and the disease is characterised by predominant involvement of subcortical structures. In 1974, Albert et al $^{7}$ after studying the neurobehavioural changes in five patients with the SRO syndrome and reviewing the literature, proposed that the pattern of intellectual impairment in the SRO syndrome corresponded to a "subcortical dementia" and could be clinically distinguished from that seen in "cortical dementias" such as Alzheimer's disease; the dementia of the SRO syndrome being characterised by forgetfulness, slow mentation, emotional or personality changes, impaired ability to manipulate acquired knowledge and the conspicuous absence of dysphasia, agnosia

Table 2 Results of neuropsychological assessment in Steele-Richardson-Olszewski syndrome

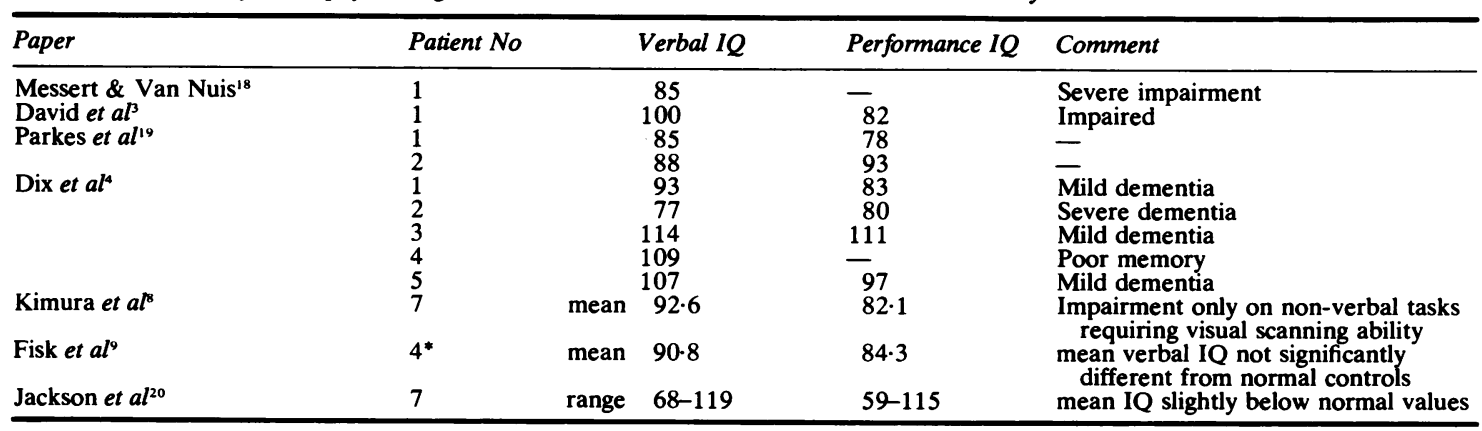

*Including two patients also included by Kimura et al.$^{8}$ 
and perceptual abnormalities. Marked dysphasia has been reported in the SRO syndrome ${ }^{24}$ but we have confirmed that in the early stages apart from mild word finding difficulties, language functions are usually unimpaired. The deficits we observed on the digit span (which involves immediate memory and the ability to reverse digits), arithmetic (the only timed verbal subtest) and similarities (which involves ability to abstract shared characteristics of the two items) subtests are compatible with observations of Albert et al. ${ }^{7}$ The impaired performance on the picture arrangement subtest in the presence of normal perception suggests that patients with SRO syndrome have a particular difficulty in arranging information in a sequential manner.

Early descriptions of the effect of frontal lobe deficits noted an impairment of "serialisation and synthesising" ability ${ }^{25}$ and a similarity between the neurobehavioural changes found in patients with "subcortical dementia" and bilateral frontal lobe damage has been noted. We have found that most patients who were assessed on tests believed to be sensitive to frontal lobe function performed poorly and that clinical signs of frontal lobe damage were common. In animal studies stimulation of lesions of the basal ganglia and the frontal cortex may have similar effects, ${ }^{26}$ and patients with other diseases affecting the basal ganglia such as Parkinson's disease are impaired on tests of the frontal lobe function. ${ }^{27} 28$ In view of the increasing evidence of the importance of subcortical structures and their cortical projections in human cognitive and perceptual processes, ${ }^{29}{ }^{30}$ further prospective studies of the performance of SRO syndrome patients on tests of frontal lobe function, and comparison of the pattern of neuropsychometric performance is the SRO syndrome and Alzheimer's disease will clearly be of interest.

We thank the Physicians of the National Hospitals for Nervous Diseases for permission to publish details of their patients and Professor Elizabeth $\mathrm{K}$ Warrington for helpful criticism and permission to publish data obtained by her department.

\section{References}

' Steele JC, Richardson JC, Olszewski J. Progressive Supranuclear Palsy. Arch Neurol 1964;10:333-59.

${ }^{2}$ David NJ, Mackey EA, Smith JL. Further observations in Progressive Supranuclear Palsy. Neurology (Minneap) 1968;18:349-56.

${ }^{3}$ Blumenthal $\mathrm{H}$, Miller C. Motor nuclear involvement in Progressive Supranuclear Palsy. Arch Neurol 1966;20:362-7.

${ }^{4}$ Dix MR, Harrison MJG, Lewis PD. Progressive Supranuclear Palsy (Steele-Richardson-Olszewski Syn- drome). A report of 9 cases with particular reference to the mechanism of the oculomotor disorder. $J$ Neurol Sci 1970;12:237-56.

5 Newman N, Gay AJ, Stroud MH, Brooks J. Defective rapid eye movements in Progressive Supranuclear Palsy. Brain 1970;93:775-84.

- Steele JC. Progressive Supranuclear Palsy. Brain 1972;95:693-704.

${ }^{7}$ Albert ML, Feldman RG, Willis AL. The subcortical dementia of Progressive Supranuclear Palsy.J Neurol Neurosurg Psychiatry 1974;37:121-30.

${ }^{8}$ Kimura D, Barnett HJM, Burkhart G. The Psychological test pattern in Progressive Supranuclear Palsy. Neuropsychologia 1981;19:301-6.

' Fisk JD, Goodale MA, Burkhart G, Barnett HJM. Progressive Supranuclear Palsy: The relationship between ocular motor dysfunction and Psychological test performance. Neurology (NY) 1982;32:698-705.

${ }^{10}$ Wechsler D. Wechsler Adult Intelligence Scale (Manual). New York: The Psychological Corporation, 1955.

" Nelson HE. The National Adult Reading Test. Windsor, Berks: NFER Publishing Co, 1982.

${ }^{12}$ Warrington EK. Deficient recognition memory in organic amnesia. Cortex 1974;10:289-91.

${ }^{13}$ McKenna P, Warrington EK. Graded Naming Test. Windsor, Berks: Nelson Publishing Co Ltd, 1983.

${ }^{14}$ Warrington EK, Taylor AM. Immediate memory for faces: long or short term memory. $Q J$ Exp Psychol 1973;25:316-22.

15 Warrington EK, James M. Disorders of visual perception in patients with localised cerebral lesions. Neuropsychologia 1967;5:253-66.

${ }^{16}$ Weigl E. On the Psychology of the so-called process of abstraction. J Abn Soc Psychol 1941;36:3-33.

${ }^{17}$ Lhermitte F. "Utilization behaviour" and its relation to lesions of the frontal lobes. Brain 1983;106:237-55.

${ }^{18}$ Messert M, Van Nuis C. A syndrome of downward gaze, dysarthria, pseudobulbar palsy, axial rigidity of neck and trunk and dementia. J Nerv Ment Dis 1966;143:47-54.

${ }^{19}$ Parkes JD, Knill-Jones RP, Clements PJ. L-dopa and amantidine hydrochloride in extrapyramidal disorders. Postgrad Med J 1971;47:116-9.

${ }^{20}$ Jackson JA, Jankovic J, Ford J. Progressive Supranuclear Palsy: Clinical features and response to treatment in 16 patients. Ann Neurol 1983;13:273-8.

${ }^{21}$ Pffafenbach DD, Layton DD, Kearns TP. Ocular manifestations in Progressive Supranuclear Palsy. Am J Ophthalmol 1972;74:1179-84.

${ }^{22}$ Ishino $\mathrm{H}$, Otsuki S. Frequency of Alzheimer's neurofibrillary tangles in the cerebral cortex in Progressive Supranuclear Palsy. J Neurol Sci 1976;28:309-16.

${ }^{23}$ Tagliavani F, Dilleri G, Gemignani F, et al. Neuronal loss in the basal nucleus of Meynert in Progressive Supranuclear Palsy. Acta Neuropathol (Berl) 1983;61:157-60.

${ }^{24}$ Perkin GD, Lees AJ, Stern GM, Kocen RS. Problems in the diagnosis of Progressive Supranuclear Palsy (Steele-Richardson-Olszewski Syndrome). Can J Neurol Sci 1978;5:167-73.

${ }^{25}$ Bianchi L. Mechanism of the Brain and Function of the 
Frontal Lobe. Edinburgh: Livingstone, 1922.

${ }^{26}$ Battig K, Rosvold HE, Mishkin M. Comparison of the effects of frontal and caudate lesions on discrimination learning in monkeys. J Comp Physiol Psychol 1962;53:400-4.

${ }^{27}$ Bowen FP. Behavioural alterations in patients with basal ganglia lesions. In: Yahr MD, ed. The Basal Ganglia. New York: Raven Press, 1976:171-89.
${ }^{28}$ Lees AJ, Smith E. Cognitive deficits in the early stages of Parkinson's disease. Brain 1983;106:257-70.

${ }^{24}$ Cummings JL, Benson DF. Subcortical dementia: Review of an emerging concept. Arch Neurol 1984;41:874-9.

${ }^{30}$ Stern Y. Behaviour and the basal ganglia. In: Mayeux R, Rosen W, eds. The Dementias. New York: Raven Press 1983:195-209. 